\title{
MAPPING SNOW COVER EXTENT USING OPTICAL AND SAR DATA
}

\author{
Anna Wendleder, Andreas J. Dietz, Katharina Schork \\ German Aerospace Center (DLR), German Remote Sensing Data Center (DFD), Land surface \\ Applications (LAX), Oberpfaffenhofen, D-82234 Wessling, anna.wendleder@dlr.de
}

\begin{abstract}
Snow cover plays an important role both globally and regionally as it is fundamental for local water availability, river run-off, and groundwater recharge. Hence, the exact knowledge of extent and dynamic of the snow coverage is essential. This study combines synergetic optical and SAR data with the main object to map the snow cover extent. As the Sentinel-Mission provides a wide swath width and a high revisit time (2-3 days at mid-latitudes with same acquisition geometry), the Sentinel-1 Interferometric Wide Swath Mode (IW) SAR data and Sentinel-2 multi-spectral data are used. Additionally, the TanDEM-X DEM is applied for the exact determination of the snow line as well as for snow classification. The mapping of the snow cover extent is applied on the three test sites Devon Island in Canada, Nordenskiöld, Svalbard, and French Alps, France which are characterized by different topography and land cover. The classification achieved an overall accuracy of $85 \%$ for Devon Island, $60 \%$ for Nordenskiöld and $88 \%$ for the French Alps.
\end{abstract}

Index Terms - Snow Cover Extent, optical data, SAR, NDSI, Sentinel-1, Sentinel-2

\section{INTRODUCTION}

Approximately half of the Northern Hemisphere is covered with snow during midwinter, making snow cover the most prevalent land-cover type during the season. The extent and the dynamic of the snow cover depend strongly on precipitation and temperature. Both parameters are subject of climate change variabilities and leads to an earlier melting and a less snow coverage. These variations have wide reaching implications on a regional scale as well as on global scale. On a global scale, snow cover is important for local water availability, river run-off, and groundwater recharge. For countries like Norway and Switzerland, where electricity is mainly generated through hydropower stations, the exact knowledge of the snow covered area is essential for water resource management, for example using when using snowmelt runoff models. Furthermore, it is reported that changes in winter snow depth influence the vegetation growth of certain land-cover types.
Optical and SAR remote sensing data enables continuous monitoring of large, remote areas. The spectral reflectivity and scattering character of snow depends among others on grain size and shape, liquid water content, snow depth and impurity of snow [1-3]. Their usage is often limited due to cloud coverage and ambiguity between snow and ice because both have similar optical properties in glacial areas. In contrast, SAR acquisitions are independent of cloud coverage and sun light and are well suited for the classification of wet snow [4-5] and the differentiation between wet snow and bare ice and hence the determination of the snow line. However, dry snow and bare ground as well as glacial ice and the surrounding land have similar backscatter characteristic. A combination of optical and SAR data would eliminate the disadvantages of each sensor. In this paper we propose an approach how optical and SAR data can be synergetic used for the classification of the snow cover extent. The snow mask derived of Sentinel-2 data is used for the analyzing of the SAR backscatter of Sentinel-1. As the snow SAR backscatter changes with the elevation, the high resolution and up-to-date TanDEM-X Digital Elevation Model (DEM) is additionally used. The main advantage of this approach is that even dry snow can be classified with SAR.

\section{STUDY SITES AND DATA}

For the validation of your algorithm we choose three test sites with different topography and land cover. The first test site is the Devon Ice Cap located in Nunavut, Canada $\left(75.42^{\circ} \mathrm{N} 83.25^{\circ} \mathrm{W}\right)$. The ice cap on eastern Devon Island covers an area over $12.000 \mathrm{~km}^{2}$ and is characterized with a very smooth topography. The highest point has an elevation of $1920 \mathrm{~m}$ a.s.l. and the lowest point located at the ocean has an elevation with $0 \mathrm{~m}$, a.s.l. The second test site is located in Nordenskiöld, Svalbard $\left(78.21^{\circ} \mathrm{N} 15.63^{\circ} \mathrm{E}\right)$, southwest of Longyearbyen. Approximately $60 \%$ of the island is covered with glaciers. The landscape is characterized by fjords and grass vegetation. The elevation ranges between $0 \mathrm{~m}$ a.s.l. at the ocean and $1700 \mathrm{~m}$ a.s.l. at the mountain peaks. The third test site is located in the French Alps, France $\left(45.91^{\circ} \mathrm{N} 6.86 \mathrm{E}\right)$ near Chamonix. The topography is very rough with steep slopes dominated by trees, larch, and alpine landscape. The elevation ranges 
between $995 \mathrm{~m}$ a.s.l. at the plateau and $4808 \mathrm{~m}$ a.s.l. with the Mont Blanc.

The mapping of the snow cover extent bases on optical and SAR data and a digital elevation model (DEM). The Sentinel-Mission provides a wide swath width and a high revisit time (2-3 days at mid-latitudes with same acquisition geometry) which will support a regular mapping and monitoring of the snow cover extent. The Sentinel-1 sensor provides C-Band SAR data. For all three test sites the Interferometric Wide Swath Mode (IW) with a geometric resolution of $10 \mathrm{~m}$ was chosen. The SAR data for Devon Ice Cap and Nordenskiöld are acquired in the $\mathrm{HH} / \mathrm{HV}$ polarization whereas the SAR data for the French Alps are acquired in the VV/VH polarization. The Sentinel-2 sensor provides multi-spectral data with 13 bands in the visible, near infrared, and short-wave infrared part of the spectrum with a geometrical resolution of $20 \mathrm{~m}$. In order to support same snow and meteorological conditions optical and SAR data of nearly the same acquisition date were chosen. Table 1 gives an overview of all used optical and SAR data for each test site.

The TanDEM-X DEM is used for the geocoding of Sentinel-1 data and for the definition of the SAR backscatter threshold for snow based on the elevation height. The DEM has a geometric resolution of $12 \mathrm{~m}$ and provides a consistent data set for all three test sites. The TanDEM-X DEM provided by the DLR is not edited, i.e. (1) water bodies are characterized by noisy, random or void values, (2) noisy DEM values along edges are smoothed and (3) outliers, radar shadow/layover and voids are interpolated. All these steps toke place in an additional TanDEM-X DEM Editing which are explained in detail in [6].

\begin{tabular}{c|c|c}
\hline Test Site & Sentinel-1 & Sentinel-2 \\
\hline Devon Ice Cap, Canada & 29.07 .2016 & 28.07 .2016 \\
& 10.08 .2016 & 11.08 .2016 \\
\hline Nordenskiöld, Svalbard & 10.07 .2017 & 10.07 .2017 \\
\hline French Alps, France & 21.05 .2016 & 16.05 .2016 \\
& 13.08 .2016 & 14.08 .2016
\end{tabular}

Table 1. Overview of Sentinel-1 and 2 acquisitions

\section{METHODOLOGY}

In a pre-step, the format of Sentinel-1 and Sentinel-2 data and TanDEM-X DEM are adapted into the same geometric frame and extent and into the same geometric resolution. The algorithm for the mapping of snow cover extent contains three main steps (Fig.1):
(1) Based on the Sentinel-2 data, a water mask, cloud mask, and snow mask are generated. The first two layers are used as auxiliary layers in order to minimize misclassifications. The water mask is manually digitalized and only provided for the both test sites on the Devon Ice Cap and in Nordenskiöld. The cloud mask is generated with the help of the tool Sen2Cor which is provided by ESA. The snow mask derived of the optical data is calculated using the Normalized-Difference Snow Index (NDSI) based on band 3 and band 12 .

(2) The snow mask derived of the NDSI is used to analyze the snow backscatter value of the Sentinel-1 scene. As the snow type and hence the snow backscatter value changes with the altitude (wet snow in lower altitudes and dry snow in higher altitudes), the elevations of the TanDEM-X DEM are separated into $50 \mathrm{~m}$ steps and each elevation step is assigned a backscatter threshold for snow.

(3) The mapping of the final snow cover extent is applied using the Sentinel-1 scene and the TanDEM-X DEM with the previously defined thresholds.

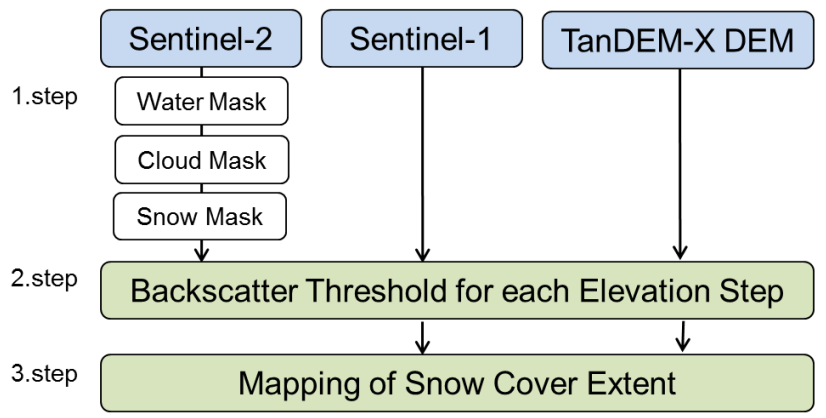

Figure 1. Workflow of the snow cover extent mapping

\section{RESULTS}

The snow masks derived of the Sentinel-1 data based on the elevation dependent backscatter threshold are compared with the snow mask derived of the Sentinel-2 based on the NDSI (Normalized Difference Snow Index). The overall accuracy of the three test sites are listed in Table 2 and ranges between $47 \%$ and $95 \%$.

For Devon Ice Cap, the snow masks are derived for the two dates on 29.07.2016 and 10./12.08.2016. In the Sentinel-1 image of 29.07.2016 a clear distinction between dry snow (higher backscatter) in the percolation zone and the wet snow (lower backscatter) in the wet snow zone is recognizable (Fig. 2a), whereas the Sentinel-2 image shows both for the percolation zone and the wet snow zone s high snow reflectivity (Fig 2b). Due to the data gap of the Sentinel-2 image in the lower right part, a second Sentinel-2 acquisition is used in order to cover the whole test site. Unfortunately, the second acquisition is cloud covered. The snow mask in Figure $2 \mathrm{c}$ shows that both the dry snow and 

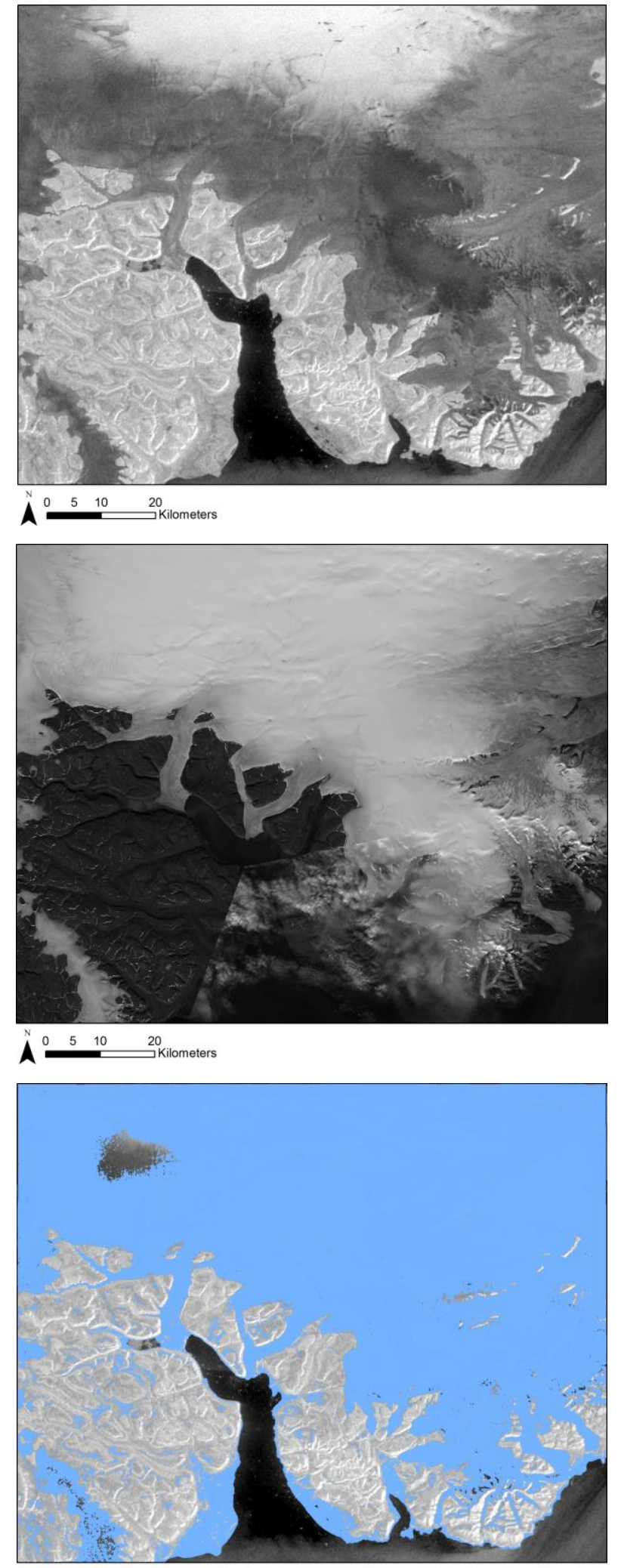

$\mathbf{A}^{0} \begin{array}{llll}0 & 10 & 20 & 20 \\ & & & \end{array}$

Figure 2. Devon Ice Cap, Canada (a) Sentinel-1 image acquired on 29.07.2016, (b) Sentinel-2 image acquired in 28.07.2016, and (c) final snow mask classified superimposed on Sentinel-1
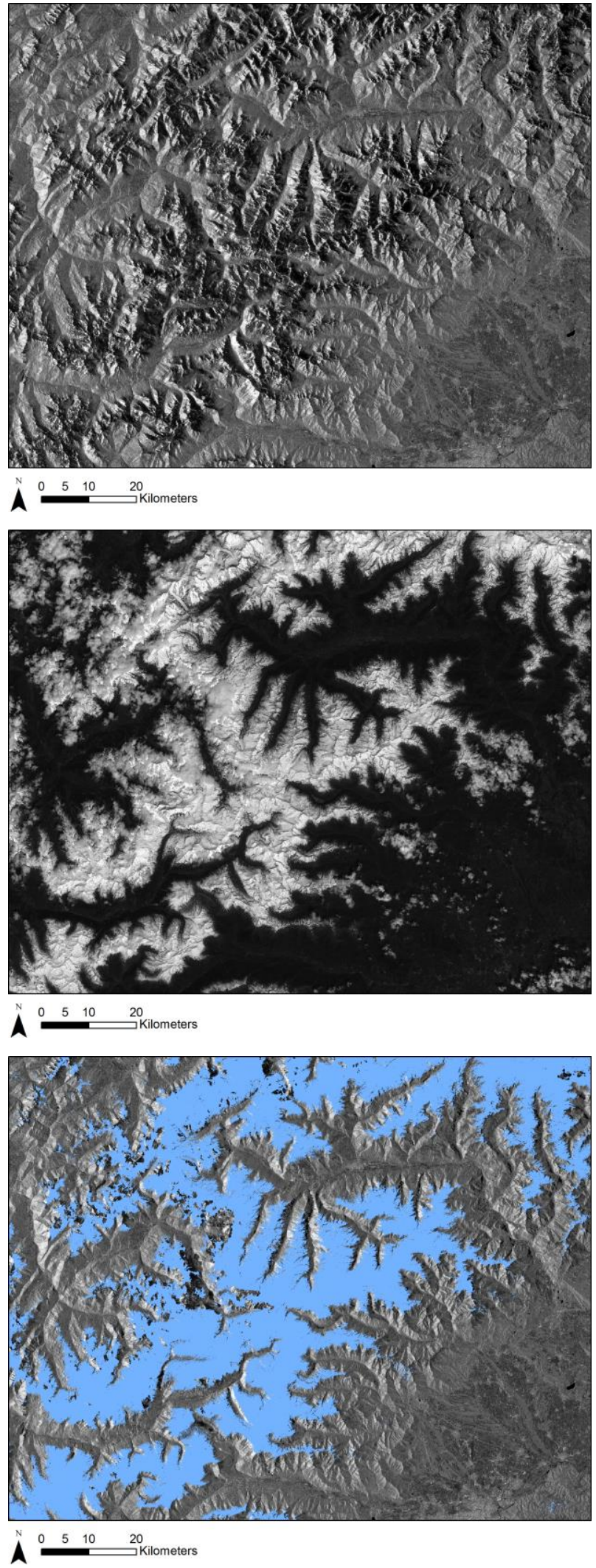

Figure 3. French Alps, France (a) Sentinel-1 image acquired on 21.05.2016, (b) Sentinel-2 image acquired in 16.05.2016, and (c) final snow mask superimposed on Sentinel-1 


\begin{tabular}{c|c|c}
\hline Test Site & $\begin{array}{c}\text { Acquisition } \\
\text { Date }\end{array}$ & $\begin{array}{c}\text { Overall } \\
\text { accuracy }\end{array}$ \\
\hline Devon Ice Cap, Canada & 29.07 .2016 & $84 \%$ \\
& $10 . / 12.08 .2016$ & $47 \%$ \\
\hline Nordenskiöld, Svalbard & 10.07 .2017 & $61 \%$ \\
\hline French Alps, France & $15 . / 21.05 .2016$ & $88 \%$ \\
& $13 . / 14.08 .2016$ & $95 \%$
\end{tabular}

Table 2. Overall accuracy of the snow classification

the wet zone are classified. In the wet snow zone, some pixels are not classified as snow probably due to their lower backscatter values compared to the backscatter values in the same elevation step. Furthermore, the bare land along the coast is misclassified as snow due to similar backscatter values of snow in the same altitude. The snow mask of 29.07.2018 has an accuracy of $84 \%$, whereas the snow mask of 10./12.08.2016 has an accuracy of $47 \%$. The low accuracy of $47 \%$ can be explained by the precipitation between 10.08 and 12.08 .2016 recorded by the automatic weather station which changed the meteorological conditions between both acquisitions.

The topography of Nordenskiöld and Devon Ice Cap are similar except the steep slopes of the fjords in Nordenskiöld. Equally, the dry snow in the higher altitudes as well as the wet snow in the lower altitudes are classified as snow. The snow mask has an overall accuracy is $61 \%$.

For the test site in the French Alps, two snow masks are derived for 16./21.05.2016 and 13./.14.08.2016. The snow masks have an overall accuracy of $88 \%$ and $95 \%$. The time delay of 5 days between the Sentinel-1 image and the Sentinel-2 image acquired in May does not influence the classification result as during this period the meteorological conditions did not change.

\section{CONCLUSION}

The importance to derive a daily snow mask using remote sensing data increases more and more. The SentinelMission provides a revisit time of 2-3 days using the same one orbit. Using the acquisitions of all available orbits enables the creation of a snow mask for every two days, but only using either Sentinel-1 or Sentinel-2 data. First, the synergy of both sensors permits a daily snow mask.

In a first approach we analyzed how optical and SAR data can be combined in order to exploit the advantages of both sensors. The main advantage of the elevation based threshold of the SAR backscatter is that it enables also the classification of wet snow as well of dry snow. In our study both multispectral and SAR data are acquired in a short time period in order to have the same meteorological conditions.
For a daily snow mask, the approach must be extended by interpolating the snow mask for the dates without any Sentinel acquisition.

\section{ACKNOWLEDGMENT}

The authors acknowledge the use of TanDEM-X data, which have been made available for scientific use via the TanDEM-X Science Service proposal "DEM_GLAC1775 Monitoring extent and dynamic of snow cover using optical and SAR data". We would like to thank the Copernicus Service for providing the Sentinel-1 and Sentinel-2 data free charge.

\section{REFERENCES}

[1] F. Domine, M. Albert, T. Huthwelker, H.-W. Jacobi, A.A. Kokhanovyks, M. Lehning, G. Picard and W.R. Simpson, "Snow physics as relevant to snow photochemistry". Atmospheric Chemistry and Physics Discussions, 2007, 7, pp. 5941-6036.

[2] M. König, J. Winther and E. Isaksson, "Measuring snow and glacier ice properties from satellite". Reviews of Geophysics, 2001, 39, pp. 1-27.

[3] A.J. Dietz, C. Kuenzer, U. Gessner and S. Dech, „Remote Sensing of snow - a review of available methods", International Journal of Remote Sensing, 2012, vol. 33, no. 13, pp. 4094-4134.

[4] T. Nagler and H. Rott, "Retrieval of Wet Snow by Means of Multitemporal SAR Data", IEEE Transactions on Geosciences and Remote Sensing, 2000, vol. 38, no. 2, pp. 754-765.

[5] D. Small, "Flattening Gamma; Radiometric Terrain Correction for SAR Imagery", IEEE Transactions on Geosciences and Remote Sensing, 2011, vol. 49, no. 8, pp. 3081-3093.

[6] M. Huber, B. Wessel, A. Wendleder, J. Hoffmann and A. Roth, "A framework for an automated editing of TanDEM-X digital elevation models". IEEE International Geoscience and Remote Sensing Symposium (IGARSS), IEEE Xplore, IGARSS 2015, Milan, Italy. 26.-31. 07. 2015, DOI: 10.1109/ IGARSS.2015.7326658 ISBN 978-1-4799-7929-5. 